\title{
Quorum sensing regulation methods and their effects on biofilm in biological waste treatment systems: $A$ review
}

\author{
Zhuqiu Sun ${ }^{1}$, Jinying Xi $(\bowtie)^{1,2}$, Chunping Yang $^{3,4}$, Wenjie Cong ${ }^{1}$
}

1 Environmental Simulation and Pollution Control State Key Joint Laboratory, School of Environment, Tsinghua University, Beijing 100084, China 2 State Environmental Protection Key Laboratory of Microorganism Application and Risk Control (SMARC), Beijing 100084, China 3 Guangdong Provincial Key Laboratory of Petrochemical Pollution Processes and Control, School of Environmental Science and Engineering, Guangdong University of Petrochemical Technology, Maoming 525099, China

4 College of Environmental Science and Engineering, Hunan University and Key Laboratory of Environmental Biology and Pollution Control (Hunan University), Ministry of Education, Changsha 410082, China

\section{H I G H L I G H T S \\ - Quorum sensing enhancement and inhibition methods are summarized. \\ - Effects of quorum sensing regulation on biofilm are reviewed. \\ - Current knowledge gaps and research challenges are proposed.}

\section{A R T I C E I N F O}

Article history:

Received 16 April 2021

Revised 10 October 2021

Accepted 11 October 2021

Available online 2 November 2021

\section{Keywords:}

Quorum sensing

Biological waste treatment

Biofilm formation

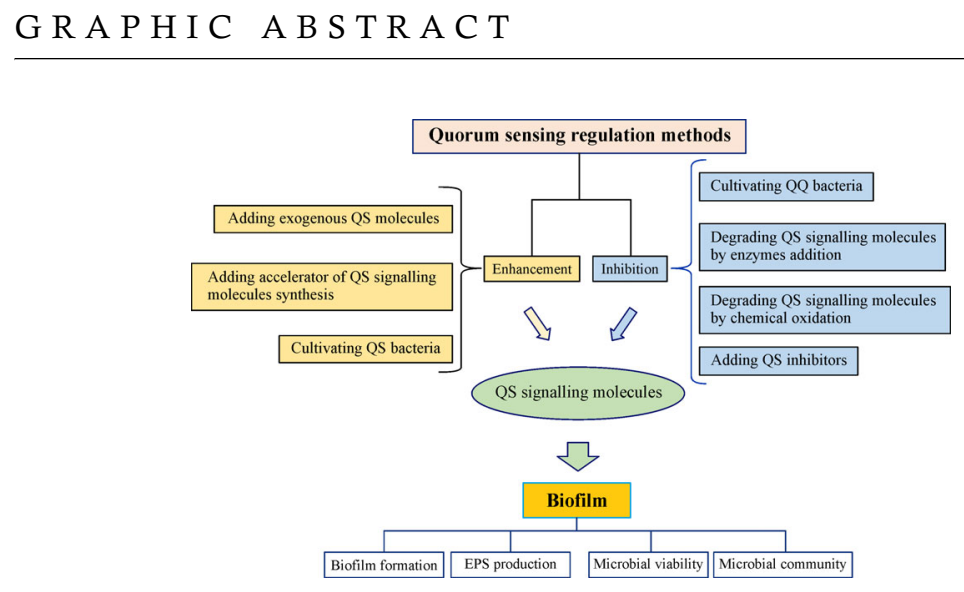

\section{A B S T R A C T}

Quorum sensing (QS) plays an important role in microbial aggregation control. Recently, the optimization of biological waste treatment systems by QS regulation gained an increasing attention. The effects of QS regulation on treatment performances and biofilm were frequently investigated. To understand the state of art of QS regulation, this review summarizes the methods of QS enhancement and QS inhibition in biological waste treatment systems. Typical QS enhancement methods include adding exogenous QS molecules, adding QS accelerants and cultivating QS bacteria, while typical QS inhibition methods include additions of quorum quenching (QQ) bacteria, QS-degrading enzymes, QS-degrading oxidants, and QS inhibitors. The specific improvements after applying these QS regulation methods in different treatment systems are concluded. In addition, the effects of QS regulation methods on biofilm in biological waste treatment systems are reviewed in terms of biofilm formation, extracellular polymeric substances production, microbial viability, and microbial community. In the end, the knowledge gaps in current researches are analyzed, and the requirements for future study are suggested.

(C) The Author(s) 2021. This article is published with open access at link.springer.com and journal.hep. com.cn

\section{Introduction}

The finding of quorum sensing (QS) has provided a new idea to regulate microbial growth (Sivasankar et al., 2019), and an increasing number of studies have been carried out

$凶$ Corresponding author

E-mail: xijinying@tsinghua.edu.cn to optimize biological waste treatment systems by QS regulation methods (Liu et al., 2015; Peng et al., 2018; Liu et al., 2020). QS signaling molecules includes N-acylhomoserine lactones (AHLs), autoinducers-2 (AI-2), autoinducing peptides (AIPs), quinolone (PQS), etc. (Holban et al., 2016; Turan et al., 2017; Maddela et al., 2019). By different effects on QS signaling molecules, QS regulation methods can be classified into two groups: QS enhancement and QS inhibition. QS enhancement methods 
aim to increase QS signaling molecules concentrations in the systems while QS inhibition methods aim to decrease QS signaling molecules concentrations or interfering its function.

There are quite a few review articles about QS regulation in biological waste treatment systems in the literatures, covering different aspects and topics. Most of these reviews are on the roles of QS regulation and its distinctive performances in biological wastewater treatment systems (Maddela et al., 2019). Many reviews summarized the application of QS enhancement methods in specific biological wastewater treatment processes such as nitrification and denitrification, partial nitritation-anammox, granular sludge system (Huang et al., 2019; Wang et al., 2021b; Zhao et al., 2021). Besides QS enhancement, there are also some reviews targeting QS inhibition to mitigate biofouling in membrane bioreactors (MBRs) (Lade et al., 2014; Siddiqui et al., 2015). Most of the reviews focused on the effects of QS regulation on the system performance, while only a few considered the effects on biofilm formation from the microbiology perspective (Huang et al., 2016; Chen et al., 2018).

Although the reviews in the literature presented a comprehensive understanding on the development of QS regulation for wastewater treatment, there are still some questions to be answered: 1) What are the specific methods to achieve QS enhancement and inhibition in biological waste treatment systems? 2) What are the effects of QS regulation on biofilm in biological waste treatment systems? In this review, we summarized the methods of QS regulation in biological waste treatment systems. The effects of QS regulation on biofilm in terms of biofilm formation, extracellular polymeric substances (EPS) production, and microbial viability and community were also reviewed.

\section{Theory of QS regulation on biofilm}

The QS systems are mediated by some signaling molecules, and general signaling molecules mainly includes AHLs, AI-2, AIPs and PQS, and their mechanism to mediate QS are shown in Fig. 1.

As shown in Fig. 1, the processes for different QS signaling molecules are quite similar. QS bacteria produce signaling molecules and secrete them to the extracellular environment. When the extracellular QS signaling molecules accumulate to a certain level in the local environment, they can enter the bacterial cell again and activate the transcription and expression of specific genes (Whiteley et al., 2017). The most widely studied QS signaling molecules are AHLs, which have been found in 25 Gramnegative bacterial species (Turan et al., 2017). The first AHLs, N-3-oxohexanoyl-1-homoserine lactone (3OC6HSL), was found in a marine bacterium Vibrio fischeri in the 1980s, and controls the expression of luminescence

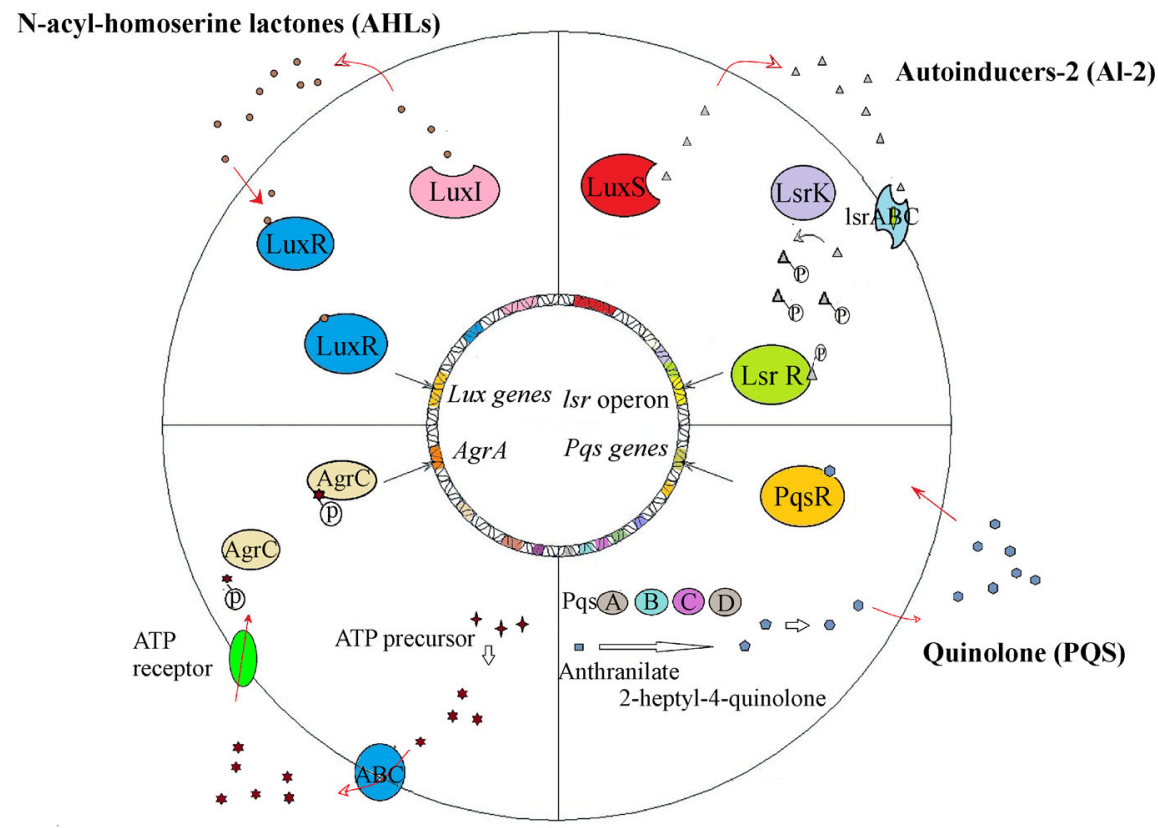

Auto-inducing peptides (AIPs)

Fig. 1 Schematic diagram of QS processes for different signaling molecules. 
(lux) genes through the Luxl/LuxR system (Eberhard et al., 1981; Engebrecht and Silverman, 1984; Whiteley et al., 2017). AHL-mediated QS affected sludge granulation and EPS production in bioreactors (Tan et al., 2014). Another important QS signaling molecule is AI-2, which was found in both Gram-positive and Gram-negative bacteria. AI-2 is produced by the participation of lux $S$ gene, and can regulate biofilm adhesion (Buck et al., 2009). AIPs, always produced by Gram-positive bacteria with two-component regulatory systems, can affect the intercellular communication, biofilm formation and microbial resistance (Sturme et al., 2002; Peterson et al., 2004). PQS, belonging to the 4-quinolone (4Q) family, is produced by Pseudomonas aeruginosa ( $P$. aeruginosa) and can regulate multicellular behaviors, denitrification and iron transport systems (Diggle et al., 2006; Fernández-Piñar et al., 2011; Maddela et al., 2019).

Quorum sensing regulation has a significant impact on biofilm formation. First, it can affect the bacterial swimming and attachment (Kjelleberg and Molin, 2002; Cui et al., 2020). For example, QS inhibition by adding porcine kidney acylase I, hampered the microbial colonization in a bioaugmented systems (Zhang et al., 2015). Second, QS signals can control the production of extracellular polysaccharide and rhamnolipid (Davey et al., 2003; Sakuragi and Kolter, 2007). The biofilm without QS signaling molecules was thin and lack of a three-dimensional structure (de Kievit and Iglewski, 2000). Finally, QS signaling molecules can regulate the activity and viability of bacterial cells (Lynch et al., 2002; Li et al., 2014). The effects of QS on biofilm have been commonly reported (Engebrecht and Silverman, 1984; Maddela et al., 2019; Zhang et al., 2021), which indicates its application in optimization of biological waste treatment systems.

\section{QS regulation methods in biological waste treatment systems}

\subsection{QS enhancement methods}

QS enhancement methods can increase the QS signaling molecule content in biofilm and then favor the start-up and operation of biological waste treatment systems. Three QS enhancement methods were introduced in Table 1.

\subsubsection{Adding exogenous QS signaling molecules}

The most common method to enhance QS is direct addition of exogenous QS signaling molecules, which provides immediate and accurate control of QS level (Hu et al., 2016a). AHLs is the most commonly-used QS signaling

Table 1 QS enhancement methods and their effects on performance of biological treatment systems

\begin{tabular}{|c|c|c|c|c|c|c|}
\hline QS enhancement methods & Additives & Concentration & Bioreactor & Indicators & Performance* & Reference \\
\hline \multirow[t]{6}{*}{$\begin{array}{l}\text { Adding exogenous QS } \\
\text { signaling molecules }\end{array}$} & C8-HSL & $100 \mathrm{nmol} / \mathrm{L}$ & MBBR & $\begin{array}{l}\mathrm{NH}_{4}^{+}-\mathrm{N} \\
\text { removal }\end{array}$ & + & Huang et al., 2020 \\
\hline & $\begin{array}{l}\text { Mixture of AHLs } \\
\text { (C6-, C8-, 3-OXO-C12- } \\
\text { and C14-HSL) }\end{array}$ & $1000 \mathrm{nmol} / \mathrm{L}$ & SBBR & COD removal & $+3 \%$ & Hu et al., 2016a \\
\hline & Quinolone & $100 \mathrm{nmol} / \mathrm{L}$ & MFC & Power density & $+30 \%$ & Monzon et al., 2016 \\
\hline & 3OC6-HSL & $10000 \mathrm{nmol} / \mathrm{L}$ & MEC & Current & - & Liu et al., 2015 \\
\hline & C6-HSL & $100 \mathrm{nmol} / \mathrm{L}$ & MBBR & $\begin{array}{l}\mathrm{NH}_{4}^{+}-\mathrm{N} \\
\text { removal }\end{array}$ & $-20 \%$ & Fan et al., 2019) \\
\hline & $\begin{array}{l}\text { Phenylethanol, } \\
\text { tryptophol, tyrosol }\end{array}$ & $10 \mu \mathrm{mol} / \mathrm{L}$ & MFC & $\begin{array}{l}\text { Current density } \\
\text { and electrons } \\
\text { transfer }\end{array}$ & + & Christwardana et al., 2019 \\
\hline \multirow{2}{*}{$\begin{array}{l}\text { Adding accelerator of QS } \\
\text { signaling molecules } \\
\text { synthesis }\end{array}$} & Boron & $60 \mu \mathrm{mol} / \mathrm{L}$ & BEFC & Voltage output & $+15 \mathrm{mV}$ & Cevik et al., 2020 \\
\hline & Fulvic acid & $0.5-1 \mathrm{mmol} / \mathrm{L}$ & $\begin{array}{l}\text { Anammox } \\
\text { system }\end{array}$ & $\begin{array}{l}\text { Nitrogen } \\
\text { removal }\end{array}$ & + & Liu et al., 2020 \\
\hline \multirow[t]{3}{*}{ Cultivating QS bacteria } & $\begin{array}{c}\text { Pseudomonas aeruginosa, } \\
\text { Vibrio harveyi, } \\
\text { Xanthomonas campestris }\end{array}$ & NA & EGSB & COD removal & + & Ding et al., 2015 \\
\hline & Sphingomonas rubra & $\begin{array}{l}10 \mathrm{~mL} \text { bacterium } \\
\text { solution with } \\
\mathrm{OD}_{600}=1.5\end{array}$ & MBBR & $\begin{array}{l}\mathrm{COD} \text { and } \mathrm{NH}_{4}{ }^{+}- \\
\mathrm{N} \text { removal }\end{array}$ & + & Wang et al., 2019 \\
\hline & $\begin{array}{l}\text { Centrifugation residual } \\
\text { Aeromonas sp. A-L3 }\end{array}$ & $\begin{array}{c}\text { Strain suspension } \\
\text { with a volume ratio } \\
\text { of } 2 \%\end{array}$ & $\begin{array}{l}\text { Aerobic granular } \\
\text { sludge reactors }\end{array}$ & COD removal & $+7 \%$ & Gao et al., 2019 \\
\hline
\end{tabular}


molecules, and the adding concentration generally range from 10 to $10000 \mathrm{nmol} / \mathrm{L}$. In most cases, direct addition of exogenous QS signaling molecules can promote the performance of bioreactors. For example, exogenous C6HSL and C8-HSL were successfully used to enhance nitrogen transformation in anaerobic ammonium oxidation process and moving bed biofilm reactor (MBBR) (Zhang et al., 2019a; Huang et al., 2020). The organics removal performance of electrochemical reactors were found to be enhanced after adding QS signaling molecules. Stable increase in electron transfer and power production capacity were observed in microbial fuel cells (MFCs) and microbial electrolysis cells (MECs) (Liu et al., 2015; Monzon et al., 2016; Christwardana et al., 2019).

However, not all biological treatment systems were optimized after the addition of signaling molecules. For example, 1000-nM AHL addition decelerated approximately $7 \%$ for COD removal and $2.6 \%$ for nitrifications of the ammonia nitrogen in sequencing biofilm batch reactor (SBBR) (Hu et al., 2016a) and addition of C6-HSL during the operation period of an MBBR significantly decreased $0.44 \%-20.29 \%$ after 16 days on the ammonia nitrogen removal (Fan et al., 2019). One disadvantage of direct addition of exogenous QS signaling molecules is its high expense. Another disadvantage is the unstable enhancement due to the quick degradation of exogenous QS signaling molecules by some quorum quenching (QQ) bacteria (Soler et al., 2018). The concentration of C6-HSL was found to decreased by more than $70 \%$ in 15 days after $500 \mathrm{nM}$ AHLs (four different AHL mixtures) was directly added into biofilm reactors (Hu et al., 2016b).

\subsubsection{Adding accelerators of QS signaling molecules} synthesis

Another method to enhance QS is adding accelerators in biological treatment systems to promote synthesis of QS signaling molecules. The reported accelerators include precursors of QS signaling molecules and accelerators for its release. For example, Boron is a well-known enhancer of QS signaling molecules because AI-2 will be activated with the formation of boron complexed to (R)-4,5dihydroxy-2,3-pentanedione (DPD) as its precursor (Chen et al., 2002; Cevik et al., 2020), and the adding of boron increased potential by almost $15 \mathrm{mV}$ in a bioelectrochemical fuel cells (Cevik et al., 2020). In addition, fulvic acid is one of accelerators for the AHL release, and 1 $\mathrm{mM}$ fulvic acid can increased total inorganic nitrogen removal rates to $1.94 \mathrm{mg}-\mathrm{N} / \mathrm{L} / \mathrm{h}$ from $1.27 \mathrm{mg}-\mathrm{N} / \mathrm{L} / \mathrm{h}$ in an anammox system (Liu et al., 2020). The advantage of adding accelerators is that the cost of accelerator is usually cheaper than those of QS signaling molecules. However, compared to directly adding exogenous QS signaling molecules, it risks failure because the synthesis processes of signaling molecules are very complex.

\subsubsection{Cultivating QS bacteria}

QS bacteria which can produce signaling molecules are found in natural environments and cultivation of QS bacteria is another option to economically enhance QS in biological treatment systems. Soler et al. (2018) found that 5 of 99 bacterial strains isolated from the leachates were QS bacteria. Zhang et al. (2020) added the supernatant of 7 AHL-producing strains from mature aerobic granular sludge to sequencing batch reactors, thus increasing the maximum concentrations of C6-HSL, C8-HSL, and N-(3oxooctanoyl)-1-homoserine lactone (3OC8-HSL) by $23 \%$, $81 \%$, and $27 \%$, respectively. The performances of biological treatment systems for ammonia, nitrogen, and organic carbon removal were improved by adding $P$. aeruginosa, which can serve as both AHL producers and pollutant degraders (Yong and Zhong, 2010). However, QS bacteria that promote pollutant removal always work more difficult than other methods of QS enhancement. The short-term addition of a QS strain (Sphingomonas rubra sp. nov.) could not significantly improve the COD and $\mathrm{NH}_{4}{ }^{+}$-N removal rates in MBBR (Wang et al., 2019). In addition, the increase of COD removal decreased to only $1 \%$ at 40 -s day from $7 \%$ at seventh day after adding Aeromonas sp. A-L3 as an AHL-producing bacteria (Gao et al., 2019). The QS bacteria may be washed out with excess biomass or inhibited by bacteria competition in biological treatment systems.

\subsection{QS inhibition methods}

QS inhibition methods can suppress the effects of QS signaling molecule by degrading signaling molecule, inhibiting the signaling molecule synthesis, or interfering its functions in biological treatment systems. Typical QS inhibition methods applied in biological waste treatment systems were introduced in Table 2.

\subsubsection{Cultivating QQ bacteria}

One common QS inhibition method is cultivating QQ strains to degrade QS signaling molecules. Many QQ strains isolated from nature have been comprehensively studied, such as Rhodococcus sp. BH4, Bacillus licheniformis T-1, Penicillium restrictum CBS 367.48 and Pseudomonas sp. HS-18 (Oh et al., 2012; Chen et al., 2020; Maddela and Meng, 2020; Wang et al., 2020a; Fakhri et al., 2021). In particular, Rhodococcus sp. BH4 is one of the most popular QQ strain (Oh et al., 2012; Oh and Lee, 2018). Genetic engineering QQ strains were also constructed by plasmid transformation (Oh et al., 2017). These QQ strains can rapidly degrade QS signaling molecule. For example, $50 \mu \mathrm{M}$ C6-HSL was completely degraded in 9 hours by a novel QQ-bacterium, Lactobacillus sp. SBR04MA, suspended in a solution $\left(\mathrm{OD}_{600}=\right.$ 
Table 2 QS inhibition methods and their effects on performance of biological waste treatment systems

\begin{tabular}{|c|c|c|c|c|c|}
\hline QS inhibition methods & Additives & Bioreactor & Indicators & Performance* & Reference \\
\hline \multirow[t]{5}{*}{$\begin{array}{l}\text { Cultivating quorum } \\
\text { quenching (QQ) strains }\end{array}$} & $\begin{array}{c}\text { Recombinant E. coli. and Rhodococcus sp. } \\
\text { BH4 }\end{array}$ & MBR & Transmembrane pressure & - & Oh et al., 2012 \\
\hline & Rhodococcus sp. BH4 & MBR & $\begin{array}{l}\text { Chemical oxygen demand } \\
\text { (COD) removal }\end{array}$ & $\approx$ & Ouyang et al., 2020 \\
\hline & Penicillium restrictum CBS 367.48 & MBR & $\begin{array}{l}\text { Sulfamethoxazole and } \\
\text { erythromycin }\end{array}$ & + & Fakhri et al., 2021 \\
\hline & Lactobacillus sp. SBR04MA & MBR & COD removal & $\approx$ & $\begin{array}{l}\text { Kampouris et al., } \\
2018\end{array}$ \\
\hline & Bacillus sp. T5 and Delftia lacustris T6 & MBR & Transmembrane pressure & - & $\begin{array}{l}\text { Yavuztürk Gül and } \\
\text { Koyuncu, } 2017\end{array}$ \\
\hline \multirow{3}{*}{$\begin{array}{l}\text { Adding degrading } \\
\text { enzymes }\end{array}$} & Acylase & MBR & COD removal & $\approx$ & Yeon et al., 2009 \\
\hline & Porcine kidney acylase I & MBR & Transmembrane pressure & - & Jiang et al., 2013b \\
\hline & Acylase & Nanofiltration & Flux profiles & + & Kim et al., 2011 \\
\hline \multirow[t]{3}{*}{$\begin{array}{l}\text { Degrading QS signaling } \\
\text { molecules by ROS }\end{array}$} & Long-wave UV & MBR & $\begin{array}{l}\text { TOC, COD, TN, TP, and } \\
\mathrm{NH}^{+}-\mathrm{N} \text { removal }\end{array}$ & $\approx$ & Zhang et al., 2019b \\
\hline & $\mathrm{TiO}_{2}$ nanoparticles under UV irradiation & MBR & COD removal & + & $\begin{array}{l}\text { Mehmood et al., } \\
2021\end{array}$ \\
\hline & Electric field & EMBR & Phenol degradation rate & + & Jiang et al., 2020 \\
\hline \multirow[t]{3}{*}{ Adding QS inhibitors } & Vanillin & RO & Biofilm formation & - & $\begin{array}{l}\text { Ponnusamy et al., } \\
2009\end{array}$ \\
\hline & 3,3',4',5-tetrachlorosalicylanilide & MBR & Ammonium removal & $\approx$ & Feng et al., 2020 \\
\hline & Piper betle extract & MBR & Transmembrane pressure & - & Siddiqui et al., 2012 \\
\hline
\end{tabular}

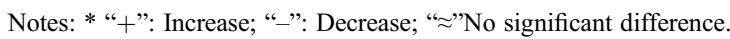

1.0) (Kampouris et al., 2018). Betaproteobacteria and Firmicutes suspensions $\left(\mathrm{OD}_{600}=1.0\right)$ could remove completely $200 \mathrm{nM}$ AHL in 30-60 s (Yavuztürk Gül and Koyuncu, 2017). The isolation and evaluation of those QQ strains provide a promising QS inhibition method for large-scale system.

The addition of QQ strains showed no significant effects on performance of biological waste treatment systems in many researches (Kampouris et al., 2018; Ouyang et al., 2020). For example, the addition of Lactobacillus sp. SBR04MA, a QQ-strain did not affect the COD removal efficiency of $95 \%$ throughout the entire operating period of an MBR. In most cases, adding QQ strains was used to control biofouling in MBRs, which was first reported in 2009 (Yeon et al., 2009). In addition, the stable operation of bioreactors after adding QQ strains indicated that the control of excessive biomass accumulation or biofouling by this QS inhibition method does not need a performance recovery period compared to other physical or chemical methods (Jiang et al., 2013b; Lee et al., 2018a; Xiao et al., 2018; Liu et al., 2021a; Wang et al., 2021a).

\subsubsection{Degrading QS signaling molecules by enzymes}

Another emerging method is direct addition of enzymes to degrade the QS signaling molecules in biological treatment systems. Many enzymes for QS signaling molecules degradation have been found and studied, particularly the enzymes for AHL degradation. Lactonase, acylase, decarboxylase and deaminase were found to be four typical enzymes having AHL degradation capacity, and the pathways of AHL degradation under these enzymes are also reported (Siddiqui et al., 2015). Among the four enzymes, acylase is most frequently used and it was observed to effectively decrease the concentration of QS signaling molecules in a MBR with COD and ammonia removal efficiencies above 95\% (Jiang et al., 2013b). Kim et al. (2011) also found that membrane flux of a nanofiltration system was increased by more than $30 \%$ after adding acylase. However, the enzymes also have a short lifetime in bioreactors and will loss activity easily, which limits their application.

\subsubsection{Degrading QS signaling molecules by reactive} oxygen species (ROS)

QS inhibition method by producing ROS including hydroxyl radicals and superoxide has gradually attracted interest in recent years (Lee et al., 2018b; Zhang et al., $2019 b$ ). For example, the ROS generated by short-time UV-TiO ${ }_{2}$ photocatalysis inactivated AI-2 secreted from Escherichia coli and reduced the bacterial biomass by 42.6\% (Xiao et al., 2016). Continuous UV photolysis or photocatalysis were also successfully applied to mitigate 
biofouling in MBR, performing more efficiently than adding QQ bacteria (Zhang et al., 2019b; Mehmood et al., 2021). In addition, the ROS generated by an electric field $(0.4 \mathrm{~V} / \mathrm{cm})$ lowered the AHLs concentrations (13-23 ng/L) compared to the control group (24-37 ng/L) in a MBR (Jiang et al., 2020). Although these new approaches showed significantly capacity to inhibit QS, their exact role and the mechanisms of QS inhibition in biological waste treatment system are still unknown.

\subsubsection{Adding QS inhibitors}

Besides removing QS signaling molecules, adding QS inhibitors to interfere QS receptors or inactivate signaling molecules was also applied in biological waste treatment systems (Yates et al., 2002; Teplitski et al., 2011; Kalia, 2013). Many QS inhibitors were found including 3-amino2-oxazolidinone YXL-13, homoserine lactone-like TGKseries, $\varepsilon$-polysine, aporphinoid alkaloids, cladodionen, gingerol, etc (Al-Shabib et al., 2020; Alibi et al., 2020; Brown et al., 2020; Cheng et al., 2020; Di Marco et al., 2020; Li et al., 2020; Parmar et al., 2020; Qin et al., 2020; Shen et al., 2020; Wang et al., 2020b). Vanillin (4hydroxy-3-methoxybenzaldehyde) was used as the QS inhibitor and decreased the biofilm formation by over $45 \%$ on reverse osmosis (RO) membrane (Ponnusamy et al., 2009). The inhibitor 3,3',4',5-tetrachlorosalicylanilide $(100 \mu \mathrm{g} / \mathrm{L})$ decreased the average AI-2 concentration by $30 \%$, and reduced the biofilm in MBR by $50 \%$ (Feng et al., 2020). The addition of easily-synthesized and economic QS inhibitors can reduce the operating cost, and thus may be more cost-effective than adding QQ strains or degrading enzymes.

\section{Effects of QS regulation on biofilm}

\subsection{Biofilm formation}

A quick biofilm formation is essential for the successful start-up of a biological waste treatment system (Xu et al., 2021). QS enhancement methods were applied to enhance biofilm formation in many researches. The biofilms formation in start-up phase and recovery from starvation on carriers was significantly accelerated in bioreactors in the presence of exogenous AHLs (Huang et al., 2016; Xiong et al., 2020). Besides AHLs, the exogenous PQS or some alcohol molecules (phenylethanol, tryptophol and tyrosol) also showed the positive effects on the biofilm growth in the MFC (Monzon et al., 2016; Christwardana et al., 2019). Laser scanning confocal microscopy (LSCM) is often used to observe biofilm formation in a QS enhancement system, but rarely giving quantitative results. We collected the LSCM images from some researches and calculated the pixels proportion of fluorescent biofilm with and without QS enhancement (Huang et al., 2016; Hu et al., 2017; Wang et al., 2018; Xiong et al., 2020). The result is shown in Fig. 2. The average percentage of biofilm in QS enhancement systems was significantly increased.

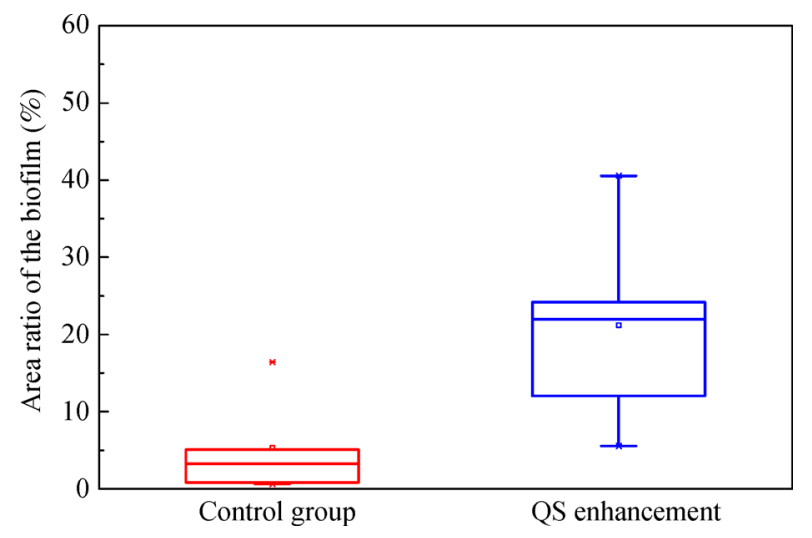

Fig. 2 Biofilm formation in QS enhanced systems observed by LSCM.

QS inhibition methods were also applied to control biofilm formation or biofouling in MBRs. Weerasekara et al. (2016) obtained LSCM images of the biofilm along the top, middle and bottom parts of the membrane fiber in a control MBR and a QS-inhibited MBR. The biofilm layer was obviously thicker and rougher in the control MBR. Similar results were observed in many other studies (Kim et al., 2011; Ergön-Can et al., 2017; Oh et al., 2017; Oh and Lee, 2018). The transmembrane pressure is the most important indicator to reflect the biofouling in MBRs. Decrease in transmembrane pressure has been frequently observed in QS-inhibited systems. In a MBR added with sodium alginate capsule-immobilized acylase to inhibit QS, the transmembrane pressure was maintained at $15 \mathrm{kPa}$, while the transmembrane pressure of control MBR was more than $40 \mathrm{kPa}$ under the same conditions (Jiang et al., 2013a). Compared with adding bactericidal agents (silver salts, nitrofurazone, ammonium surfactants or antibacterial peptides), QS inhibition methods for biofouling control are much safer to the environment.

\subsection{EPS production}

EPS, which is dominated by polysaccharide (PS) and proteins $(\mathrm{PN})$, are closely related to the microbial attachment and biofilms structure. The positive effect of AHLs on EPS production in different bioreactors such as SBBR, MBBR and MFC was the most frequently reported compared with other QS signaling molecule content (Chen et al., 2017; Fan et al., 2019). The adding of AHLs can even increase exponentially EPS production in biofilm. For example, the addition of AHLs caused increased the PS content by approximately more than 1 time during the stable operation of an MBBR (Liu et al., 2021b). Except 
for AHLs, the adding Al-2 was found can promote EPS production in a bioreactor (Ding et al., 2015). However, the positive effect of QS enhancement for other QS signaling molecule content such as PQS and AIPs on EPS production is lack solid evidence. There are some QS signaling molecule such as diffusible signal factor (DSF), 3OC6-HSL, 3-oxo-C10-HSL might have no significant positive or negative effect on EPS production in biological treatment systems (Ding et al., 2015; Lv et al., 2018; Wang et al., 2018; Huang et al., 2019), and the reason why those QS signaling molecule had opposite EPS trends with increasing their content $\mathrm{s}$ in bioreactors is still not understood. These molecules should be avoided in similar conditions if the aim is to increase the EPS production.

The general current consensus is that most of QS inhibition significantly decreases the EPS production by from less than $10 \%$ to more than $70 \%$ (see Table 3), and many studied were carried out in MBR to control biofouling on a laboratory scale (Shi et al., 2017; Iqbal et al., 2018; Yu et al., 2018). The AHLs is the main target signaling molecule of QS inhibition because its QQ bacteria might be more easily isolated and obtained. For example, when QQ strains that degrade C6-HSL, C8-HSL, and $\mathrm{N}$-decanoyl-1-homoserine lactone (C10-HSL) were added to a laboratory-scale anaerobic MBR, the EPS production decreased by $72 \%, 36 \%$ and $66 \%$, respectively (Xu et al., 2020). In addition, although the decreasing EPS production reduces the amount of biofouling, it also causes excessive shedding of the biofilm that destroyed the biofilm function, which may explain why QS inhibition is rarely used to solve the biomass accumulation in bioreactors with biofilms as the functional main body.
Therefore, more accurate control of EPS production is required for widening the application scope of QS inhibition, and the quantitative relationship between EPS production and decreased content of different QS signaling molecules should be investigated more in other bioreactors, especially biofilm reactors.

\subsection{Microbial viability}

The positive effects of QS enhancement on microbial viability were found by semiquantitative analysis in several bioreactors. Pan et al. (2020) observed the double fluorescence stained biofilm on the anode of an MFC fed with C6-HSL and 3-OXO-C12-HSL, and they found that its microbial viability was significantly higher than that without exogenous AHLs. Similar results were also observed in a mixed-culture MFC fed with C4-HSL, C6HSL and 3-OXO-C12-HSL and a bioelectrochemical system fed with C6-HSL and 3-OXO-C12-HSL (Chen et al., 2017; Fang et al., 2018). Although these studies directly observed the live/dead bacteria and their local distributions, they could not accurately quantify the ratio of live to dead bacteria. Therefore, we recommend the use of flow cytometry and enzyme activity assays that quantify the live/dead bacteria ratio and metabolic activity in QSenhanced systems.

Many previous studies suggested that the microbial viability of bacteria biofilm was always decreased by the QS inhibition methods. For example, the cell viability of Agrobacterium tumefaciens was decreased to $77 \%-80 \%$ of its original level by adding the QS-degrading acylase at concentrations of $0.1-10 \mu \mathrm{g} / \mathrm{mL}$, indicating that the QS

Table 3 EPS production in QS inhibited systems

\begin{tabular}{|c|c|c|c|c|c|c|}
\hline Methods of QS inhibition & Target signal molecule & Bioreactor & Wastewater & Sampling time & EPS production* & Reference \\
\hline QQ consortia & AHLs & MBR & Domestic & $59 \mathrm{~d}$ & $\begin{array}{c}-55 \% \text { (Protein) } \\
-60 \% \text { (Carbohydrates) }\end{array}$ & Yu et al., 2018 \\
\hline $\begin{array}{l}\text { Facultative QQ consor- } \\
\text { tiums-C6 }\end{array}$ & C6-HSL & MBR & Domestic & $7 \mathrm{~d}$ & $-72 \%$ & Xu et al., 2020 \\
\hline $\begin{array}{l}\text { Facultative QQ consor- } \\
\text { tiums-C8 }\end{array}$ & C8-HSL & & & & $-36 \%$ & \\
\hline $\begin{array}{l}\text { Facultative QQ consor- } \\
\text { tiums-C10 }\end{array}$ & C10-HSL & & & & $-66 \%$ & \\
\hline Rhodococcus sp. BH4 & AHLs & MBR & $\begin{array}{l}\text { Synthetic and } \\
\text { municipal }\end{array}$ & $100 \mathrm{~d}$ & $\begin{array}{c}-9 \% \text { (Protein) } \\
-9 \% \text { (Carbohydrates) }\end{array}$ & Iqbal et al., 2018 \\
\hline Rhodococcus sp. BH4 & AHLs & MBR & Synthetic & $80 \mathrm{~d}$ & $\begin{array}{c}-70 \% \text { (Protein) } \\
-50 \% \text { (Carbohydrates) }\end{array}$ & $\begin{array}{l}\text { Weerasekara et al., } \\
2016\end{array}$ \\
\hline $\begin{array}{l}\text { Recombinant Escherichia } \\
\text { coli TOP10-AiiO }\end{array}$ & AHLs & $\mathrm{RO}$ & Synthetic & $109 \mathrm{~h}$ & $\begin{array}{c}-35 \% \text { (Protein) } \\
-43 \% \text { (Polysaccharides) }\end{array}$ & Oh et al., 2017 \\
\hline $\begin{array}{l}\text { Acylase-Immobilized } \\
\text { Nanofiltration Membrane }\end{array}$ & AHLs & Nanofiltration & Synthetic & $5 \mathrm{~d}$ & - (Polysaccharides) & Kim et al., 2011 \\
\hline Rhodococcus sp. BH4 & AHLs & MBR & Synthetic & $30 \mathrm{~d}$ & $\begin{array}{c}-25 \% \text { (Polysaccharides) } \\
-50 \% \text { (Protein) }\end{array}$ & $\begin{array}{l}\text { Ergön-Can et al., } \\
2017\end{array}$ \\
\hline
\end{tabular}

Notes: * “+”: Increase; “-”: Decrease; “\%” Relative percentage. 
inhibition had a negative impact on viability (Bao et al., 2020). A double mutant $P$. aeruginosa strain ( $\Delta$ las $R \Delta r h l R$ and $\Delta$ lasI $\Delta r h l I)$ showed lower survival ability than the wild-type strain (Lu et al., 2010). Interestingly, the effect of QS inhibition on microbial viability in mixed culture was opposite to that in pure culture. For example, fewer dead cells and more viable cells were observed in the biofilms in a QS-inhibited MBR by fluorescent staining method (Oh et al., 2017). The decrease in the number of dead cells was also observed in the biofilm samples in a seawater desalination RO membrane treated by AI-1 QS inhibitors (Katebian et al., 2016). Oh et al. (2017) suggested that the QS inhibition may result in slower maturation of biofilm.

\subsection{Microbial community}

Many genera were found that they would be prompted with the QS enhancement in biofilm. Pseudomonas is one of the most common genera, and a significant increasing of its abundance has been found with AHL-mediated QS enhancement in many biological treatment reactors such as SBBR, MBBR, and MFC (Hu et al., 2017; Zhang et al., 2019a; Huang et al., 2020; Pan et al., 2020; Zhang et al., 2020), which is consistent with the results of studies on the effects of AHLs on this genus (Davies et al., 1998; Kjelleberg and Molin, 2002; Cellini et al., 2020). Meanwhile, the abundance of Nitrosomonas, a major class of nitrifying bacteria (Phanwilai et al., 2020; Qiu et al., 2020), increases with increasing content of signaling molecules. This trend is thought to explain (at least partly) why QS enhancement can optimize biological treatment reactors for ammonia nitrogen removal ( $\mathrm{Li}$ et al., 2015; Hu et al., 2017; Zhang et al., 2019a). In addition, the abundance of Methanosaeta, which can produce methane and degrade organic matter, is commonly increased by the addition of AHLs (Lv et al., 2018; Ma et al., 2019). Directly using an electron transfer mechanism, the relative abundance of Geoboacter was increased in some electrochemical reactors with biofilm by adding exogenous AHLs that promoted organic matter degradation (Chen et al., 2017; Pan et al., 2020).

Some of genera with significantly decreased relative abundances were also shown in the results of highthroughput sequencing for the microbial community in QS-enhanced systems. For example, significant decreases in the relative abundance of Pseudorhodoferax and Thiothrix as the dominant bacteria were found in an SBBR with the adding AHLs and cultivating AHLproducing strains, respectively, and the growth of Paracoccus was inhibited in two QS-enhanced SBBRs $(\mathrm{Hu}$ et al., 2016a; Zhang et al., 2020). These results further indicate that QS can effectively regulate the microbial community, and QS enhancement can optimize many biological treatment systems in the start-up stage.

Two commonalities of microbial community in biofilm with QS inhibition were found. First, in studies that monitored the bacterial composition, the effects of QS inhibition on the bacterial composition tended to weaken after long running times of the reactors. This result is probably because other types of signal molecules are constantly secreted, and QS inhibition cannot decrease the levels of all of them, which results in a complex environment in the middle and late phases of the QSinhibited system operation and weakens the effects of QS inhibition on the microbial community (Ouyang et al., 2020). Second, endogenous QS and QQ bacteria are always sensitive to decreased levels of QS signaling molecules. Ouyang et al. (2020) reported that the abundance of QQ bacteria Comamonadaceae increased from 24\% to 29\%, and that of QS bacteria Cytophagaceae decreased from $13 \%$ to $10 \%$ in MBRs after QS inhibition. In another study, the increased abundance of QQ bacteria Rhodococcus and Stenotrophomonas and decreased abundance of QS bacteria Aeromonas occurred in EMBRs as the levels of AHLs decreased (Jiang et al., 2020). Although many studies have reported decreased abundances of QS bacteria and increased abundance of QQ bacteria with QS inhibition in biological treatment systems, the mechanism of QS signaling molecules acting on QS bacteria and QQ bacteria remains unclear. Understanding the relationship between QS inhibition and the microbial community is important for optimizing biological treatment systems. It also provides an opportunity for controlling the microbial function of biofilm. The latent rules underlying the relationship between the microbial community and QS inhibition in biological treatment systems for pollutant removal hiding in previous studies need to be further excavated.

\section{Conclusions and perspectives}

Typical QS enhancement methods and inhibition methods employed in biological waste treatment systems are summarized in this review. The effects of QS regulation on biofilm are also introduced. Generally, QS enhancement can help to increase the biofilm formation and thus promote the pollutants removal performance of different types of bioreactors. Meanwhile, QS inhibition can help to mitigate biofouling in membrane bioreactors. Although there are great achievements in the field of QS regulation for biological waste treatment system, there are still many questions unknown and problems that should be solved. Thus, the demands for future study are listed as below:

1) The performances of different $Q S$ enhancement or inhibition methods in biological waste treatment systems should be compared. Comprehensive and quantitative evaluation on different QS regulation methods should be carried out on more types of bioreactors, such as waste gas or solid waste treatment systems.

2) The distribution, metabolism and fate of QS signaling molecules in different biological waste treatment 
systems.

3) The changes in microbial community structure and functions by QS regulation should be comprehensively studied using the molecular tools such as metagenomics and metatranscriptomics analysis to understand its mechanisms.

4) Most studies on QS regulation in biological treatment systems have been conducted on laboratory scales rather than in large-scale applications. The effects and mechanisms of QS regulation in large-scale biological treatment systems should be further studied.

In the future, the QS regulation methods will function as a promising and eco-friendly options to optimize the performance of biological waste treatment systems.

Acknowledgements This research was supported by the National Natural Science Foundation of China (Grant No. 52070113).

Open Access This article is licensed under a Creative Commons Attribution 4.0 International License, which permits use, sharing, adaptation, distribution and reproduction in any medium or format, as long as you give appropriate credit to the original author(s) and the source, provide a link to the Creative Commons licence, and indicate if changes were made. The images or other third party material in this article are included in the article's Creative Commons licence, unless indicated otherwise in a credit line to the material. If material is not included in the article's Creative Commons licence and your intended use is not permitted by statutory regulation or exceeds the permitted use, you will need to obtain permission directly from the copyright holder. To view a copy of this licence, visit http://creativecommons.org/licenses/by/4.0/.

\section{References}

Al-Shabib N A, Husain F M, Rehman M T, Alyousef A A, Arshad M, Khan A, Masood Khan J, Alam P, Albalawi T A, Shahzad S A, Syed J B, Al-Ajmi M F (2020). Food color 'Azorubine' interferes with quorum sensing regulated functions and obliterates biofilm formed by food associated bacteria: An in vitro and in silico approach. Saudi Journal of Biological Sciences, 27(4): 1080-1090

Alibi S, Ben Selma W, Ramos-Vivas J, Smach M A, Touati R, Boukadida J, Navas J, Ben Mansour H (2020). Anti-oxidant, antibacterial, anti-biofilm, and anti-quorum sensing activities of four essential oils against multidrug-resistant bacterial clinical isolates. Current Research in Translational Medicine, 68(2): 59-66

Bao Q, Hosoe A, Hosomi M, Terada A (2020). Quorum quenching acylase impacts the viability and morphological change of Agrobacterium tumefaciens cells. Journal of Bioscience and Bioengineering, 130(1): 82-88

Brown M M, Kwiecinski J M, Cruz L M, Shahbandi A, Todd D A, Cech N B, Horswill A R (2020). Novel peptide from commensal staphylococcus simulans blocks methicillin-resistant staphylococcus aureus quorum sensing and protects host skin from damage. Antimicrobial Agents and Chemotherapy, 64(6): e00172-20

Buck B L, Azcárate-Peril M A, Klaenhammer T R (2009). Role of autoinducer-2 on the adhesion ability of Lactobacillus acidophilus. Journal of Applied Microbiology, 107(1): 269-279

Cellini A, Donati I, Fiorentini L, Vandelle E, Polverari A, Venturi V, Buriani G, Vanneste J L, Spinelli F (2020). N-acyl homoserine lactones and lux solos regulate social behaviour and virulence of pseudomonas syringae pv. actinidiae. Microbial Ecology, 79(2): 383396

Cevik E, Tombuloglu H, Anıl I, Senel M, Sabit H, Abdulazeez S, Borgio J F, Barghouthi M (2020). Direct electricity production from Microalgae Choricystis sp. and investigation of the boron to enhance the electrogenic activity. International Journal of Hydrogen Energy, 45(19): 11330-11340

Chen B, Peng M, Tong W, Zhang Q, Song Z (2020). The quorum quenching bacterium bacillus licheniformis T-1 protects Zebrafish against aeromonas hydrophila infection. Probiotics and Antimicrobial Proteins, 12(1): 160-171

Chen H, Li A, Cui D, Wang Q, Wu D, Cui C, Ma F (2018). N-Acylhomoserine lactones and autoinducer-2-mediated quorum sensing during wastewater treatment. Applied Microbiology and Biotechnology, 102(3): 1119-1130

Chen S, Jing X, Tang J, Fang Y, Zhou S (2017). Quorum sensing signals enhance the electrochemical activity and energy recovery of mixedculture electroactive biofilms. Biosensors \& Bioelectronics, 97: 369 376

Chen X, Schauder S, Potier N, Van Dorsselaer A, Pelczer I, Bassler B L, Hughson F M (2002). Structural identification of a bacterial quorumsensing signal containing boron. Nature, 415(6871): 545-549

Cheng W J, Zhou J W, Zhang P P, Luo H Z, Tang S, Li J J, Deng S M, Jia A Q (2020). Quorum sensing inhibition and tobramycin acceleration in Chromobacterium violaceum by two natural cinnamic acid derivatives. Applied Microbiology and Biotechnology, 104(11): 5025-5037

Christwardana M, Frattini D, Duarte K D Z, Accardo G, Kwon Y (2019). Carbon felt molecular modification and biofilm augmentation via quorum sensing approach in yeast-based microbial fuel cells. Applied Energy, 238: 239-248

Cui T, Bai F, Sun M, Lv X, Li X, Zhang D, Du H (2020). Lactobacillus crustorum ZHG 2-1 as novel quorum-quenching bacteria reducing virulence factors and biofilms formation of Pseudomonas aeruginosa. Lebensmittel-Wissenschaft + Technologie, 117: 108696

Davey M E, Caiazza N C, O'Toole G A (2003). Rhamnolipid surfactant production affects biofilm architecture in Pseudomonas aeruginosa PAO1. Journal of Bacteriology, 185(3): 1027-1036

Davies D G, Parsek M R, Pearson J P, Iglewski B H, Costerton J W, Greenberg E P (1998). The involvement of cell-to-cell signals in the development of a bacterial biofilm. Science, 280(5361): 295-298

de Kievit T R, Iglewski B H (2000). Bacterial quorum sensing in pathogenic relationships. Infection and Immunity, 68(9): 4839-4849

Di Marco N I, Pungitore C R, Lucero-Estrada C S M (2020). Aporphinoid alkaloids inhibit biofilm formation of Yersinia enterocolitica isolated from sausages. Journal of Applied Microbiology, 129(4): 1029-1042

Diggle S P, Cornelis P, Williams P, Cámara M (2006). 4-quinolone signalling in Pseudomonas aeruginosa: Old molecules, new perspectives. International Journal of Medical Microbiology, 296 (2-3): 83-91

Ding Y, Feng H, Huang W, Shen D, Wang M (2015). A sustainable method for effective regulation of anaerobic granular sludge: Artificially increasing the concentration of signal molecules by cultivating a secreting strain. Bioresource Technology, 196: 273-278 
Eberhard A, Burlingame A L, Eberhard C, Kenyon G L, Nealson K H, Oppenheimer N J (1981). Structural identification of autoinducer of Photobacterium fischeri luciferase. Biochemistry, 20(9): 2444-2449

Engebrecht J, Silverman M (1984). Identification of genes and gene products necessary for bacterial bioluminescence. Proceedings of the National Academy of Sciences of the United States of America, 81 (13): 4154-4158

Ergön-Can T, Köse-Mutlu B, Koyuncu İ, Lee C H (2017). Biofouling control based on bacterial quorum quenching with a new application: Rotary microbial carrier frame. Journal of Membrane Science, 525: 116-124

Fakhri H, Shahi A, Ovez S, Aydin S (2021). Bioaugmentation with immobilized endophytic Penicillium restrictum to improve quorum quenching activity for biofouling control in an aerobic hollow-fiber membrane bioreactor treating antibiotic-containing wastewater. Ecotoxicology and Environmental Safety, 210: 111831

Fan X, Peng P, Huang H, Peng C, Gao Y, Ren H (2019). Undesirable effects of exogenous $\mathrm{N}$-acyl homoserine lactones on moving bed biofilm reactor treating medium-strength synthetic wastewater. Science of the Total Environment, 696: 134061

Fang Y, Deng C, Chen J, Lü J, Chen S, Zhou S (2018). Accelerating the start-up of the cathodic biofilm by adding acyl-homoserine lactone signaling molecules. Bioresource Technology, 266: 548-554

Feng X, Guo W, Zheng H, Yang S, Du J, Wu Q, Luo H, Zhou X, Jin W, Ren N (2020). Inhibition of biofouling in membrane bioreactor by metabolic uncoupler based on controlling microorganisms accumulation and quorum sensing signals secretion. Chemosphere, 245: 125363

Fernández-Piñar R, Cámara M, Dubern J F, Ramos J L, Espinosa-Urgel M (2011). The Pseudomonas aeruginosa quinolone quorum sensing signal alters the multicellular behaviour of Pseudomonas putida KT2440. Research in Microbiology, 162(8): 773-781

Gao M, Liu Y, Liu Z, Li H, Zhang A (2019). Strengthening of aerobic sludge granulation by the endogenous acylated homoserine lactonessecreting strain Aeromonas sp. A-L3. Biochemical Engineering Journal, 151: 107329

Holban A M, Gestal M C, Grumezescu A M (2016). Control of biofilmassociated infections by signaling molecules and nanoparticles. International Journal of Pharmaceutics, 510(2): 409-418

$\mathrm{Hu} \mathrm{H}$, He J, Liu J, Yu H, Tang J, Zhang J (2016a). Role of N-acylhomoserine lactone (AHL) based quorum sensing on biofilm formation on packing media in wastewater treatment process. RSC Advances, 6(14): 11128-11139

Hu H, He J, Liu J, Yu H, Zhang J (2016b). Biofilm activity and sludge characteristics affected by exogenous $\mathrm{N}$-acyl homoserine lactones in biofilm reactors. Bioresource Technology, 211: 339-347

$\mathrm{Hu} \mathrm{H}$, He J, Yu H, Liu J, Zhang J (2017). A strategy to speed up formation and strengthen activity of biofilms at low temperature. RSC Advances, 7(37): 22788-22796

Huang H, Fan X, Peng P, Peng C, Gao Y, Zhang X, Ren H (2020). Two birds with one stone: Simultaneous improvement of biofilm formation and nitrogen transformation in MBBR treating high ammonia nitrogen wastewater via exogenous $\mathrm{N}$-acyl homoserine lactones. Chemical Engineering Journal, 386: 124001

Huang J, Shi Y, Zeng G, Gu Y, Chen G, Shi L, Hu Y, Tang B, Zhou J
(2016). Acyl-homoserine lactone-based quorum sensing and quorum quenching hold promise to determine the performance of biological wastewater treatments: An overview. Chemosphere, 157: 137-151

Huang J, Yi K, Zeng G, Shi Y, Gu Y, Shi L, Yu H (2019). The role of quorum sensing in granular sludge: Impact and future application: A review. Chemosphere, 236: 124310

Iqbal T, Lee K, Lee C H, Choo K H (2018). Effective quorum quenching bacteria dose for anti-fouling strategy in membrane bioreactors utilizing fixed-sheet media. Journal of Membrane Science, 562: 1825

Jiang B, Zeng Q, Hou Y, Li H, Liu J, Xu J, Shi S, Ma F (2020). Impacts of long-term electric field applied on the membrane fouling mitigation and shifts of microbial communities in EMBR for treating phenol wastewater. Science of the Total Environment, 716: 137139

Jiang Q, Rentschler J, Perrone R, Liu K (2013a). Application of ceramic membrane and ion-exchange for the treatment of the flowback water from Marcellus shale gas production. Journal of Membrane Science, 431: 55-61

Jiang W, Xia S, Liang J, Zhang Z, Hermanowicz S W (2013b). Effect of quorum quenching on the reactor performance, biofouling and biomass characteristics in membrane bioreactors. Water Research, 47 (1): 187-196

Kalia V C (2013). Quorum sensing inhibitors: An overview. Biotechnology Advances, 31(2): 224-245

Kampouris I D, Karayannakidis P D, Banti D C, Sakoula D, Konstantinidis D, Yiangou M, Samaras P E (2018). Evaluation of a novel quorum quenching strain for MBR biofouling mitigation. Water Research, 143: 56-65

Katebian L, Gomez E, Skillman L, Li D, Ho G, Jiang S C (2016). Inhibiting quorum sensing pathways to mitigate seawater desalination RO membrane biofouling. Desalination, 393: 135-143

Kim J H, Choi D C, Yeon K M, Kim S R, Lee C H (2011). Enzymeimmobilized nanofiltration membrane to mitigate biofouling based on quorum quenching. Environmental Science \& Technology, 45(4): 1601-1607

Kjelleberg S, Molin S (2002). Is there a role for quorum sensing signals in bacterial biofilms? Current Opinion in Microbiology, 5(3): 254258

Lade H, Paul D, Kweon J H (2014).N-acyl homoserine lactone-mediated quorum sensing with special reference to use of quorum quenching bacteria in membrane biofouling control. BioMed Research International, 2014: 162584

Lee K, Park J S, Iqbal T, Nahm C H, Park P K, Choo K H (2018a). Membrane biofouling behaviors at cold temperatures in pilot-scale hollow fiber membrane bioreactors with quorum quenching. Biofouling, 34(8): 912-924

Lee K, Yu H, Zhang X, Choo K H (2018b). Quorum sensing and quenching in membrane bioreactors: Opportunities and challenges for biofouling control. Bioresource Technology, 270: 656-668

Li A J, Hou B L, Li M X (2015). Cell adhesion, ammonia removal and granulation of autotrophic nitrifying sludge facilitated by N-acylhomoserine lactones. Bioresource Technology, 196: 550-558

Li T, Sun X, Chen H, He B, Mei Y, Wang D, Li J (2020). Methyl anthranilate: A novel quorum sensing inhibitor and anti-biofilm agent against Aeromonas sobria. Food Microbiology, 86: 103356 
Li Y, Hao W, Lv J, Wang Y, Zhong C, Zhu J (2014). The role of N-acyl homoserine lactones in maintaining the stability of aerobic granules. Bioresource Technology, 159: 305-310

Liu J, Sun F, Zhang P, Zhou Y (2021a). Integrated powdered activated carbon and quorum quenching strategy for biofouling control in industrial wastewater membrane bioreactor. Journal of Cleaner Production, 279: 123551

Liu L, Ji M, Wang F, Tian Z, Wang T, Wang S, Wang S, Yan Z (2020). Insight into the short-term effect of fulvic acid on nitrogen removal performance and $\mathrm{N}$-acylated- ${ }_{\mathrm{L}}$-homoserine lactones (AHLs) release in the anammox system. Science of the Total Environment, 704: 135285

Liu T, Xu J, Tian R, Quan X (2021b). Enhanced simultaneous nitrification and denitrification via adding $\mathrm{N}$-acyl-homoserine lactones (AHLs) in integrated floating fixed-film activated sludge process. Biochemical Engineering Journal, 166: 107884

Liu W, Cai W, Ma A, Ren G, Li Z, Zhuang G, Wang A (2015). Improvement of bioelectrochemical property and energy recovery by acylhomoserine lactones (AHLs) in microbial electrolysis cells (MECs). Journal of Power Sources, 284: 56-59

Lu Q, Yu J, Yang X, Wang J, Wang L, Lin Y, Lin L (2010). Ambroxol interferes with Pseudomonas aeruginosa quorum sensing. International Journal of Antimicrobial Agents, 36(3): 211-215

Lv L, Li W, Zheng Z, Li D, Zhang N (2018). Exogenous acylhomoserine lactones adjust community structures of bacteria and methanogens to ameliorate the performance of anaerobic granular sludge. Journal of Hazardous Materials, 354: 72-80

Lynch M J, Swift S, Kirke D F, Keevil C W, Dodd C E R, Williams P (2002). The regulation of biofilm development by quorum sensing in Aeromonas hydrophila. Environmental Microbiology, 4(1): 18-28

Ma H, Ma S, Luo W, Ding L, Wang J, Ren H (2019). Long-term exogenous addition of synthetic acyl homoserine lactone enhanced the anaerobic granulation process. Science of the Total Environment, 696: 133809

Maddela N R, Meng F (2020). Discrepant roles of a quorum quenching bacterium (Rhodococcus sp. BH4) in growing dual-species biofilms. Science of the Total Environment, 713: 136402

Maddela N R, Sheng B, Yuan S, Zhou Z, Villamar-Torres R, Meng F (2019). Roles of quorum sensing in biological wastewater treatment: A critical review. Chemosphere, 221: 616-629

Mehmood C T, Waheed H, Tan W, Xiao Y (2021). Photocatalytic quorum quenching: A new antifouling and in-situ membrane cleaning strategy for an external membrane bioreactor coupled to UASB. Journal of Environmental Chemical Engineering, 9(4): 105470

Monzon O, Yang Y, Li Q, Alvarez P J J (2016). Quorum sensing autoinducers enhance biofilm formation and power production in a hypersaline microbial fuel cell. Biochemical Engineering Journal, 109: 222-227

Oh H S, Lee C H (2018). Origin and evolution of quorum quenching technology for biofouling control in MBRs for wastewater treatment. Journal of Membrane Science, 554: 331-345

Oh H S, Tan C H, Low J H, Rzechowicz M, Siddiqui M F, Winters H, Kjelleberg S, Fane A G, Rice S A (2017). Quorum quenching bacteria can be used to inhibit the biofouling of reverse osmosis membranes. Water Research, 112: 29-37

Oh H S, Yeon K M, Yang C S, Kim S R, Lee C H, Park S Y, Han J Y, Lee J K (2012). Control of membrane biofouling in MBR for wastewater treatment by quorum quenching bacteria encapsulated in microporous membrane. Environmental Science \& Technology, 46(9): 48774884

Ouyang Y, Hu Y, Huang J, Gu Y, Shi Y, Yi K, Yang Y (2020). Effects of exogenous quorum quenching on microbial community dynamics and biofouling propensity of activated sludge in MBRs. Biochemical Engineering Journal, 157: 107534

Pan J, Hu J, Liu B, Li J, Wang D, Bu C, Wang X, Xiao K, Liang S, Yang J, Hou H (2020). Enhanced quorum sensing of anode biofilm for better sensing linearity and recovery capability of microbial fuel cell toxicity sensor. Environmental Research, 181: 108906

Parmar P, Shukla A, Rao P, Saraf M, Patel B, Goswami D (2020). The rise of gingerol as anti-QS molecule: Darkest episode in the LuxR-mediated bioluminescence saga. Bioorganic Chemistry, 99: 103823

Peng P, Huang H, Ren H, Ma H, Lin Y, Geng J, Xu K, Zhang Y, Ding L (2018). Exogenous $\mathrm{N}$-acyl homoserine lactones facilitate microbial adhesion of high ammonia nitrogen wastewater on biocarrier surfaces. Science of the Total Environment, 624: 1013-1022

Peterson S N, Sung C K, Cline R, Desai B V, Snesrud E C, Luo P, Walling J, Li H, Mintz M, Tsegaye G, Burr P C, Do Y, Ahn S, Gilbert J, Fleischmann R D, Morrison D A (2004). Identification of competence pheromone responsive genes in Streptococcus pneumoniae by use of DNA microarrays. Molecular Microbiology, 51(4): 1051-1070

Phanwilai S, Kangwannarakul N, Noophan P, Kasahara T, Terada A, Munakata-Marr J, Figueroa L A (2020). Nitrogen removal efficiencies and microbial communities in full-scale IFAS and MBBR municipal wastewater treatment plants at high COD:N ratio. Frontiers of Environmental Science \& Engineering, 14(6): 115

Ponnusamy K, Paul D, Kweon J H (2009). Inhibition of quorum sensing mechanism and aeromonas hydrophila biofilm formation by vanillin. Environmental Engineering Science, 26(8): 1359-1363

Qin X, Thota G K, Singh R, Balamurugan R, Goycoolea F M (2020). Synthetic homoserine lactone analogues as antagonists of bacterial quorum sensing. Bioorganic Chemistry, 98: 103698

Qiu S, Liu J, Zhang L, Zhang Q, Peng Y (2020). Sludge fermentation liquid addition attained advanced nitrogen removal in low $\mathrm{C} / \mathrm{N}$ ratio municipal wastewater through short-cut nitrification-denitrification and partial anammox. Frontiers of Environmental Science \& Engineering, 15(2): 26

Sakuragi Y, Kolter R (2007). Quorum-sensing regulation of the biofilm matrix genes (pel) of Pseudomonas aeruginosa. Journal of Bacteriology, 189(14): 5383-5386

Shen C, Islam M T, Masuda Y, Honjoh K I, Miyamoto T (2020). Transcriptional changes involved in inhibition of biofilm formation by $\varepsilon$-polylysine in Salmonella Typhimurium. Applied Microbiology and Biotechnology, 104(12): 5427-5436

Shi Y, Huang J, Zeng G, Gu Y, Chen Y, Hu Y, Tang B, Zhou J, Yang Y, Shi L (2017). Exploiting extracellular polymeric substances (EPS) controlling strategies for performance enhancement of biological wastewater treatments: An overview. Chemosphere, 180: 396-411 
Siddiqui M F, Rzechowicz M, Harvey W, Zularisam A W, Anthony G F (2015). Quorum sensing based membrane biofouling control for water treatment: A review. Journal of Water Process Engineering, 7: $112-122$

Siddiqui M F, Sakinah M, Singh L, Zularisam A W (2012). Targeting Nacyl-homoserine-lactones to mitigate membrane biofouling based on quorum sensing using a biofouling reducer. Journal of Biotechnology, 161(3): 190-197

Sivasankar P, Poongodi S, Seedevi P, Sivakumar M, Murugan T, Loganathan S (2019). Bioremediation of wastewater through a quorum sensing triggered MFC: A sustainable measure for waste to energy concept. Journal of Environmental Management, 237: 84-93

Soler A, Arregui L, Arroyo M, Mendoza J A, Muras A, Álvarez C, García-Vera C, Marquina D, Santos A, Serrano S (2018). Quorum sensing versus quenching bacterial isolates obtained from MBR plants treating leachates from municipal solid waste. International Journal of Environmental Research and Public Health, 15(5): 1019

Sturme M H J, Kleerebezem M, Nakayama J, Akkermans A D L, Vaughan E E, de Vos W M (2002). Cell to cell communication by autoinducing peptides in gram-positive bacteria. Antonie van Leeuwenhoek, 81: 233-243

Tan C H, Koh K S, Xie C, Tay M, Zhou Y, Williams R, Ng W J, Rice S A, Kjelleberg S (2014). The role of quorum sensing signalling in EPS production and the assembly of a sludge community into aerobic granules. The ISME Journal, 8(6): 1186-1197

Teplitski M, Mathesius U, Rumbaugh K P (2011). Perception and degradation of $\mathrm{N}$-acyl homoserine lactone quorum sensing signals by mammalian and plant cells. Chemical Reviews, 111(1): 100-116

Turan N B, Chormey D S, Büyükpınar Ç, Engin G O, Bakirdere S (2017). Quorum sensing: Little talks for an effective bacterial coordination. Trends in Analytical Chemistry, 91: 1-11

Wang H, Liao L, Chen S, Zhang L H (2020a). A quorum quenching bacterial isolate contains multiple substrate-inducible genes conferring degradation of diffusible signal factor. Applied and Environmental Microbiology, 86(7): e02930-19

Wang H, Ma D, Shi W, Yang Z, Cai Y, Gao B (2021a). Formation of disinfection by-products during sodium hypochlorite cleaning of fouled membranes from membrane bioreactors. Frontiers of Environmental Science \& Engineering, 15(5): 102

Wang J, Liu Q, Ma S, Hu H, Wu B, Zhang X X, Ren H (2019). Distribution characteristics of $\mathrm{N}$-acyl homoserine lactones during the moving bed biofilm reactor biofilm development process: Effect of carbon/nitrogen ratio and exogenous quorum sensing signals. Bioresource Technology, 289: 121591

Wang M, Zhao L, Wu H, Zhao C, Gong Q, Yu W (2020b). Cladodionen is a potential quorum sensing inhibitor against Pseudomonas aeruginosa. Marine Drugs, 18(4): 205

Wang N, Gao J, Liu Y, Wang Q, Zhuang X, Zhuang G (2021b). Realizing the role of $\mathrm{N}$-acyl-homoserine lactone-mediated quorum sensing in nitrification and denitrification: A review. Chemosphere, 274: 129970

Wang X, Wang W, Li Y, Zhang J, Zhang Y, Li J (2018). Biofilm activity, ammonia removal and cell growth of the heterotrophic nitrifier, Acinetobacter sp., facilitated by exogenous N-acyl-homoserine lactones. RSC Advances, 8(54): 30783-30793
Weerasekara N A, Choo K H, Lee C H (2016). Biofouling control: Bacterial quorum quenching versus chlorination in membrane bioreactors. Water Research, 103: 293-301

Whiteley M, Diggle S P, Greenberg E P (2017). Progress in and promise of bacterial quorum sensing research. Nature, 551(7680): 313-320

Xiao X, Zhu W W, Liu Q Y, Yuan H, Li W W, Wu L J, Li Q, Yu H Q (2016). Impairment of biofilm formation by $\mathrm{TiO}_{2}$ photocatalysis through quorum quenching. Environmental Science \& Technology, 50(21): 11895-11902

Xiao Y, Waheed H, Xiao K, Hashmi I, Zhou Y (2018). In tandem effects of activated carbon and quorum quenching on fouling control and simultaneous removal of pharmaceutical compounds in membrane bioreactors. Chemical Engineering Journal, 341: 610-617

Xiong F, Zhao X, Wen D, Li Q (2020). Effects of N-acyl-homoserine lactones-based quorum sensing on biofilm formation, sludge characteristics, and bacterial community during the start-up of bioaugmented reactors. Science of the Total Environment, 735: 139449

Xu B, Albert Ng T C, Huang S, Shi X, Ng H Y (2020). Feasibility of isolated novel facultative quorum quenching consortiums for fouling control in an AnMBR. Water Research, 169: 115251

Xu Y, Lu Z, Sun W, Zhang X (2021). Influence of pore structure on biologically activated carbon performance and biofilm microbial characteristics. Frontiers of Environmental Science \& Engineering, 15(6): 131

Yates E A, Philipp B, Buckley C, Atkinson S, Chhabra S R, Sockett R E, Goldner M, Dessaux Y, Cámara M, Smith H, Williams P (2002). Nacylhomoserine lactones undergo lactonolysis in a $\mathrm{pH}-$, temperature-, and acyl chain length-dependent manner during growth of Yersinia pseudotuberculosis and Pseudomonas aeruginosa. Infection and Immunity, 70(10): 5635-5646

Yavuztürk Gül B, Koyuncu I (2017). Assessment of new environmental quorum quenching bacteria as a solution for membrane biofouling. Process Biochemistry, 61: 137-146

Yeon K M, Lee C H, Kim J (2009). Magnetic enzyme carrier for effective biofouling control in the membrane bioreactor based on enzymatic quorum quenching. Environmental Science \& Technology, 43(19): 7403-7409

Yong Y C, Zhong J J (2010). N-Acylated homoserine lactone production and involvement in the biodegradation of aromatics by an environmental isolate of Pseudomonas aeruginosa. Process Biochemistry, 45(12): 1944-1948

Yu H, Qu F, Zhang X, Wang P, Li G, Liang H (2018). Effect of quorum quenching on biofouling and ammonia removal in membrane bioreactor under stressful conditions. Chemosphere, 199: 114-121

Zhang B, Li W, Guo Y, Zhang Z, Shi W, Cui F, Lens P N L, Tay J H (2020). A sustainable strategy for effective regulation of aerobic granulation: Augmentation of the signaling molecule content by cultivating AHL-producing strains. Water Research, 169: 115193

Zhang J, Li J, Zhao B H, Zhang Y C, Wang X J, Chen G H (2019a). Long-term effects of $\mathrm{N}$-acyl-homoserine lactone-based quorum sensing on the characteristics of ANAMMOX granules in highloaded reactors. Chemosphere, 218: 632-642

Zhang K, Zheng X, Shen D S, Wang M Z, Feng H J, He H Z, Wang S, Wang J H (2015). Evidence for existence of quorum sensing in a 
bioaugmented system by acylated homoserine lactone-dependent quorum quenching. Environmental Science and Pollution Research International, 22(8): 6050-6056

Zhang Q, Fan N S, Fu J J, Huang B C, Jin R C (2021). Role and application of quorum sensing in anaerobic ammonium oxidation (anammox) process: A review. Critical Reviews in Environmental Science and Technology, 51(6): 626-648
Zhang X, Lee K, Yu H, Mameda N, Choo K H (2019b). Photolytic quorum quenching: A new anti-biofouling strategy for membrane bioreactors. Chemical Engineering Journal, 378: 122235

Zhao Z C, Xie G J, Liu B F, Xing D F, Ding J, Han H J, Ren N Q (2021). A review of quorum sensing improving partial nitritation-anammox process: Functions, mechanisms and prospects. Science of the Total Environment, 765: 142703 